\title{
An Engineering and Educational Technology Team Approach to Introducing New Unsaturated Soils Mechanics Material into Introductory Undergradu- ate Geotechnical Engineering Courses
}

\section{Mr. Arthur Ornelas Jr., Arizona State University}

Arthur Omelas is currently a PhD student in Educational Technology in the Mary Lou Fulton Teachers College at Arizona State University. He spent fifteen years teaching in the public school and has been an adjunct instructor since 2006.

\section{Mr. John Sadauskas, Arizona State University}

John Sadauskas is a Ph.D. in Educational Technology with a concentration in Arts, Media and Engineering at Arizona State University. His research interests include social media, narrative storytelling, cyberlearning, embodied mixed-media learning, affective computing, and instructional design. He holds a M.Ed. in Curriculum and Instruction from Arizona State University and is a former middle/high school English teacher. His work is steeped in a multi-disciplinary background including education, design, filmmaking, music, programming, sociology, literature and journalism. He is a member of ASU's Advancing Next Generation Learning Environments (ANGLE) and Reflective Living research groups.

Dr. Sandra Houston, Arizona State University

Dr. Sandra Houston is a member of the Geotechnical Engineering faculty in the School of Sustainable Engineering and the Built Environment at Arizona State University.

\section{Wilhelmina C. Savenye Ph.D., Arizona State University}

Dr. Wilhelmina "Willi" C. Savenye is a professor and program leader in Educational Technology at Arizona State University. She previously taught at the University of Texas at Austin and San Diego State University. She earned her M.Ed. and Ph.D. in Educational Technology from ASU, and B.A/ in Anthropology from the University of Washington. Dr. Savenye focuses on instructional design and evaluation of technology-based and online learning systems, employing both quantitative and qualitative research methodologies. She has published over 70 articles and book chapters; made over 140 conference presentations and workshops in the U.S., Europe and Asia; been awarded numerous grants, and has produced many digital learning programs. She serves as associate editor of the Journal of Applied Instructional Design. She has served on the editorial boards of journals including Educational Technology: Research and Development and the Quarterly Review of Distance Education, and reviews for additional journals. She serves on the editorial board for the Encyclopedia of Educational Technology and has held elected leadership positions. Dr. Savenye's instructional design and evaluation work has been conducted in such diverse settings as school districts, museums, botanical gardens, zoos, universities, corporations, and Army tank maintenance training.

\section{Eddy Ramirez}

Eddy Ramirez is a graduate research assistant and graduate student in the School of Sustainable Engineering at Arizona State University. Ramirez is fascinated in the geotechnical engineering discipline.

\section{Dr. Claudia E. Zapata, Arizona State University}

Dr. Zapata is a recognized expert in the characterization and modeling of fluid flow and volume change behavior of arid and semi-arid (unsaturated) soil mechanics. She is the author of more than 40 technical publications and multiple research reports in the areas of unsaturated soil mechanics, environmental effects in pavement design, and unbound material characterization. While Dr. Zapata possesses an excellent analytical and theoretical background in these areas, she has also significant experience in laboratory testing and instrumentation of resilient modulus and unsaturated soil characterization. Her contributions to pavement design has allowed for practical implementation of novel and complex approaches to fluid flow theory on unsaturated porous materials. 
An Engineering and Educational Technology Team Approach to Introducing New Unsaturated Soils Mechanics Material into Introductory Undergraduate Geotechnical Engineering Courses:

Cross-Curricular Coordination \& Working Outside of Your Comfort Zone

by A. Ornelas, W. Savenye, J. Sadauskas, S. Houston, C. Zapata and E. Ramirez

Arizona State University 


\begin{abstract}
:
The undergraduate geotechnical engineering introductory course has not been significantly modified in decades in U.S. universities, and to date, there is no significant coverage of unsaturated soil mechanics. Meanwhile, $74 \%$ of U.S. geotechnical faculty respondents to a recent survey indicated that unsaturated soils mechanics should be introduced at the undergraduate level. A student's depth of understanding of soils as an engineering material would be greatly enhanced via introduction of geotechnical principles for unsaturated (three phase) conditions, with the saturated soil case being presented as a subset of the broader theory.

Goals for this project include the development, piloting, dissemination, and institutionalization of lecture and laboratory modules for educating undergraduate students in the basic principles of unsaturated soils theory and the application of these principles to problems of movement of structural foundation systems. Engineering and educational technology team experiences in development of these modules and in implementation at home and partner institutions will be discussed, with an emphasis on updating the Science, Technology, Engineering, and Mathematics (STEM) curriculum in an environment in which change is often difficult.
\end{abstract}




\section{Introduction}

History dictates that in geotechnical engineering undergraduate classes, saturated soil material is the focal point of the learning content in foundations technology (Fredlund, Rahardjo, \& Fredlund, 2012). This has been the case because of the introduction of the single effective stress concept for saturated soils (Terzaghi, 1936) and the development of geotechnical engineering with a strong emphasis on saturated soil conditions. This is also the case because saturated soil approaches using a single stress state variable are, in general, simpler than unsaturated approaches where two independent stress state variables are required for solution to most geotechnical engineering problems For these reasons, learning materials, textbooks, and lecture content developed by geotechnical engineering faculty have generally taught the saturated soil model. However, in the field, the process of foundation construction based on saturated soil guidelines can be a very costly endeavor, and frequently is unnecessarily conservative.

Considering that most construction is on unsaturated soils and there is a reduced cost and effort required to build on unsaturated soils, coupled with the improved safety of construction on unsaturated soils, a shift in mentality regarding engineering for saturated versus unsaturated soils is occurring. A recent survey conducted by members of this team of geotechnical engineering faculty found that there is a "gap" in dissemination of content in unsaturated soil mechanics. Of the thirty-nine professors recently surveyed (Zapata and Houston, 2010), twenty-nine, or 74.5\% replied "Yes", when asked, "Do you believe it is important to introduce unsaturated soil mechanics principles at the undergraduate level?" In addition, thirty-two of the thirty-nine, or 82.1\% replied "Yes" when asked, "Would you be willing to test prepared lecture modules on unsaturated soils in your introductory geotechnical engineering course?" With that in mind, we 
are attempting, through this National Science Foundation funded project, to address the issue of lack of unsaturated soil material in undergraduate classes by developing learning modules on the stress state variables that govern unsaturated soils with an emphasis in concepts related to matric suction; along with laboratory techniques to obtain the Soil-Water Characteristic Curve (SWCC) such as the Axis Translation technique used in suction measurement devices such as the pressure plate. Extensive research has been conducted on unsaturated soil mechanics, but the application of these results to the undergraduate curriculum has been slow. This is partly due to the perceived complexity of soil testing and analysis. We hope to address these issues through the development of this content. The goal is to have material instructors of undergraduate geotechnical engineering classes can incorporate into their current curriculum. The challenge is two-fold: 1. that we develop material that can be seamlessly introduced into a curriculum that is already in place, and 2. that the material can be used at institutions across the country. This is especially challenging considering that Soil Mechanics curricula differ to some significant extent across the country, and the world for that matter. We plan to suggest what the best soil characteristics are for the laboratory testing module, with an emphasis on obtaining data over a wide range in suction within a reasonable period of time. For instance, to address challenge 2, coauthor Eddy Ramirez conducted tests on soil samples to determine what the optimal soil characteristics are for conducting Tempe cell tests in the laboratory. With this information we can suggest the best soil for testing to gain the desired results in a reasonable amount of time. As education professionals, we understand the importance for the student to achieve the desired result. This helps the students understand the process as well as give them the confidence in getting the "correct" answer. 
The design of the learning material follows well-established principles in instructional design. One such principle is the idea that in order for learning material to be most effective students must be actively engaged, as noted by Merrill (2007) and Van Merrienboer and Kirschner (2007). We are building the learning modules using the methods of such noted design theorists as Dick, Carey, and Carey (2005), as well as Gagne, Wager, Golas, and Keller (2005) who call for systematic procedures in instructional design, development and evaluation. The field of instructional design also suggests that students not only learn the material, but are supported in developing a fundamental change in attitude towards how they view the material, in this case unsaturated soil mechanics. Therefore our goal is three-fold: 1) for students to learn the principles of unsaturated soil mechanics; 2) for them to transfer this knowledge beyond the classroom (which in this case would be the professional field of engineering); and 3) for students to experience a change in how they view unsaturated soil mechanics, in regards to geotechnical engineering. Our aim is for students ultimately to see how important it is for them to know and apply this material professionally. This change in their behavior and thinking is paramount to the basic concepts of instructional design.

\section{Collaboration in Design Teams}

Collaboration among disciplines has been a long-standing practice in the development of instruction, though the related work processes are not often examined. Such collaboration in the area of instructional design can yield effective learning materials for students. An effective learning module can have two positive outcomes: 1) Ala student who learns more effectively and efficiently, thus enjoying the learning process more, and 2) an instructor who feels he or she has helped the student grow, learn and thrive in the discipline being taught. The learning satisfaction of the student and the job satisfaction of the teacher can also produce a more motivated 
individual, thus increasing the productivity of both. The Integrative Graduate Education

Research Traineeship (IGERT) grant initiative instituted by the National Science Foundation was set up to encourage interdisciplinary collaboration. That being said, the idea of interdisciplinary teamwork is gaining importance in solving issues in education. Although the focus of the IGERT is graduate level collaboration, the need for this type of interdisciplinary work is just as relevant at the undergraduate level.

Houston and Zapata, like many professors in engineering, realize that unsaturated soil content is covered at the graduate level. However, they also believe that introducing students to this material at the undergraduate level would benefit the field of geotechnical engineering. Developing a better knowledge base about unsaturated soils would better prepare undergraduate students for the workforce and for graduate school.

\section{Setting Up the Team}

This process began with a National Science Foundation (NSF) Transforming Undergraduate Education in Science (TUES) grant proposal written primarily by Dr. Sandra Houston, Dr. Claudia Zapata, both professors in the Ira A. Fulton Schools of Engineering, and Dr. Wilhelmina "Willi" Savenye, a professor in the Mary Lou Fulton Teachers College, all at Arizona State University. Once the project was funded, the team moved forward. Dr. Houston and Dr. Zapata first recruited Robert Garrett as the engineering research assistant (RA). In May of 2012 Garrett graduated and Eddy Ramirez was brought on board as the RA. In November of 2011 Dr. Savenye approached two PhD students in the Educational Technology program, Arthur Ornelas and John Sadauskas, as research assistants, who joined in January of 2012 


\section{Content in Unsaturated Soil Mechanics}

Subject Matter Experts (SME) in geotechnical engineering, Dr. Sandra Houston, Dr. Claudia Zapata, along with RA Eddy Ramirez, are the leads in the idea-generating process for what goes into the learning content module. Working with these experts helps the instructional design team, Dr. Willi Savenye, and RAs John Sadauskas and Arthur Ornelas, gain a better understanding of the unsaturated soils learning content.

The learning modules will consist of unsaturated soil mechanics lecture content with an emphasis on the stress state variables that control the behavior of soil under unsaturated conditions. These stress state variables are matric suction and net normal stress. Emphasis will also be placed on the transition from unsaturated soil conditions to saturated soil conditions. One key element of the implementation of unsaturated soil theory is that the stress state variables controlling soil strength and deformation behavior are measurable in the laboratory and in the field. The primary method of measurement of matric suction, axis translation, is covered in a laboratory learning module.

\section{Axis Translation}

Material covering axis translation and the role it plays in establishing the soil-water content curve (SWCC) will be addressed through a pre-laboratory learning module. The learning module will also include instructional material for laboratory exercises with the following areas of emphasis:

Tempe Cells and their role in measuring the amount of matric suction $\left(\mathrm{u}_{\mathrm{a}}-\mathrm{u}_{\mathrm{w}}\right)$ at different soil water contents. The inclusion of material that involves the measurement and plotting of points on the soil-water characteristic curve using the Tempe Cell is important because this device is more affordable than the oedometer-type pressure plate cells (the 
Fredlund Soil Water Characteristic device, or the SWC 150, Padilla, et al, 2006).

However, the Tempe Cell can only be used to measure or control matric suction, whereas there are two stress state variables that control the behavior of unsaturated soils: matric suction and net normal stress. A school could purchase a Tempe Cell device for approximately $\$ 500$ whereas an oedometer-type pressure place device could run approximately $\$ 10,000$. A university could purchase several Tempe Cell devices at a much more affordable rate, thus providing more lab opportunities for their students. Still, if this option is selected, only matric suction measurement, using axis translation, will be demonstrated. This directly relates to the flexibility of the learning module, particularly from a cost perspective.

The oedometer-type soil-water characteristic curve (SWCC) device laboratory exercises will also be included in the learning module, where the oedometer pressure plate device is capable of controlling both net normal stress and matric suction simultaneously. This more expensive, yet more generally applicable, tool is very effective in establishing plots on the soil-water content curve, and in establishing the effect of both stress state variables on soil volume change and compressibility. Because of its cost, some universities may have trouble purchasing enough to build a laboratory that would serve a large undergraduate engineering program, however, it is important to include material on the oedometer-type device for determination of SWCC since students may be required to use this device in their professional careers. 


\section{Baseline Student Knowledge Survey - Unsaturated Soils}

\section{Survey Methodology}

Once the team was established we began the preliminary process of developing a survey to be used to collect baseline data regarding what the average undergraduate knows about unsaturated soils once he or she has completed a "typical" geotechnical engineering class. This survey was designed to measure students' knowledge about unsaturated soils at the end of the normal introductory geotechnical engineering undergraduate course, without the students being exposed to the new modules. This would provide baseline data to compare with results of the survey in upcoming semesters, after students in the introductory course have experienced the new learning content.

The survey was developed primarily by the Engineering members of the development team, in collaboration with the Educational Technology members. As the team designed the survey, a few items were adjusted; for instance, some items were split into two clearer items. The final version of the survey included nine questions on unsaturated soil technology and a tenth qualitative question regarding the perceived level of difficulty of the material. (The survey can be found in Appendix A.)

Twenty-one students participated in the survey, administered to students in the CEE 351 Introduction to Geotechnical Engineering Class at Arizona State University - Tempe. This class is required for all majors in Civil Engineering. The university's course description is: Index properties and engineering characteristics of soils. Compaction, permeability and seepage, compressibility and settlement, and shear strength. The university states the enrollment requirements for the class as: Pre-requisites: BSE Civil Engineering students; CEE 213 (Introduction to Deformable Solids) with C or better. This class is four credit hours, three in- 
class credits and a one-credit lab. Instruction for the course and the lab was in-class. The professor of record was Dr. Chris Lawrence.

Students completed the survey after they had received instruction on unsaturated soil typically found in an undergraduate geotechnical engineering class at Arizona State.

\section{Survey Results}

Results of the baseline survey of student knowledge about unsaturated soils, at the end of their summer undergraduate course, did confirm the need for developing the module of instruction.

Overall performance of the 21 students across the nine-item knowledge survey was $50.79 \%$. A summary of their performance on the individual items is shown in Figure 1.

\section{PERCENTAGE CORRECT}

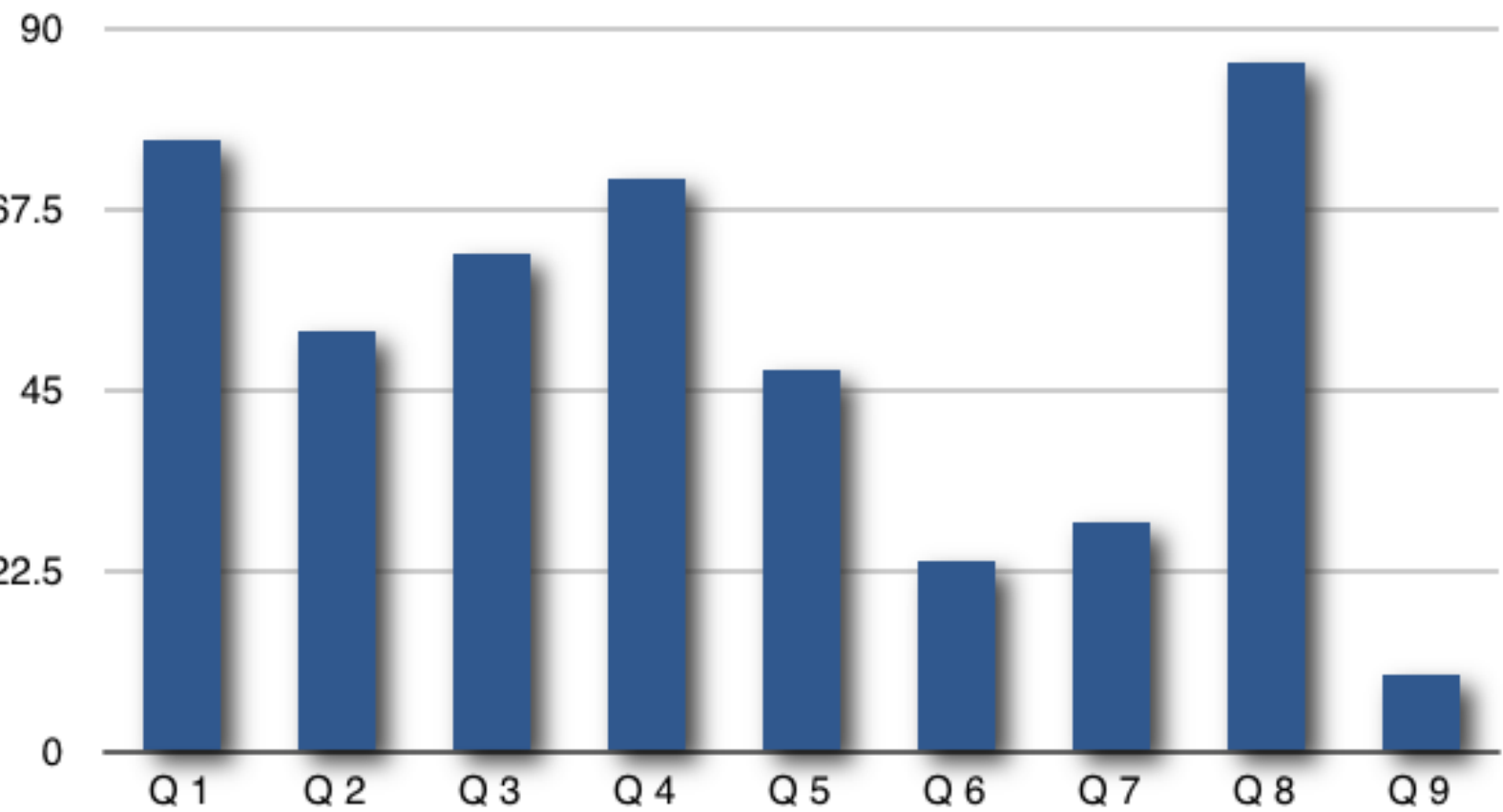

Figure 1. Students' performance on the 9 items on the baseline survey of knowledge about unsaturated soils. 
The frequency of each student response is as follows (Bold indicates the correct response):

\begin{tabular}{|c|c|c|c|c|c|}
\hline & Response 1 & Response 2 & Response 3 & Response 4 & Response 5 \\
\hline Question 1 & $3(14.29 \%)$ & $2(9.52 \%)$ & $0(0 \%)$ & $0(0 \%)$ & $16(76.19 \%)$ \\
\hline Question 2 & $1(4.76 \%)$ & $7(33.33 \%)$ & $1(4.76 \%)$ & $11(52.38 \%) 1$ & $(4.76 \%)$ \\
\hline Question 3 & $1(4.76 \%)$ & $13(61.9 \%)$ & $2(9.52 \%)$ & $1(4.76 \%)$ & $4(19.05 \%)$ \\
\hline Question 4 & $5(23.81 \%)$ & $15(71.43 \%)$ & $0(0 \%)$ & $1(4.76 \%)$ & -- \\
\hline Question 5 & $10(47.62 \%)$ & $3(14.29 \%)$ & $4(19.05 \%)$ & $4(19.05 \%)$ & -- \\
\hline Question 6 & $9(42.86 \%)$ & $3(14.29 \%)$ & $5(23.81 \%)$ & $2(9.52 \%)$ & $2(9.52 \%)$ \\
\hline Question 7 & $6(28.58 \%)$ & $1(4.76 \%)$ & $6(28.58 \%)$ & $7(33.33 \%)$ & $1(4.76 \%)$ \\
\hline Question 8 & $1(4.76 \%)$ & $1(4.76 \%)$ & $1(4.76 \%)$ & $18(85.71 \%)$ & $0(0 \%)$ \\
\hline Question 9 & $7(33.33 \%)$ & $2(9.52 \%)$ & $1(4.76 \%)$ & $7(33.33 \%)$ & $4(19.05 \%)$ \\
\hline
\end{tabular}

With a correct response rate of $85.71 \%$ it would appear that the students found question 8 ,

When an unsaturated soil is wetted under load, its response depends on: 1) the initial soil water content, 2) the amount of load applied, 3) the initial dry density of the soil, 4) a, b, and c or 5) none of the above.

to be the easiest. In contrast, question 9:

In the laboratory testing of unsaturated soils, the axis translation method: 1) is used to convert effective stresses to total stresses, 2) can be used to controlled soil suction, 3) is used in the performance of moisture-density tests (e.g. Standard Proctor), 4) is used to convert values of water content to values of soil suction, or 5) none of the above.

proved to be the most difficult for the students to grasp with only a rate of $9.52 \%$ correct. One possible explanation of this may be that Dr. Lawrence mentioned the use of the term "axis translation" (placed in bold above but not in bold on the actual student survey) as one the students may not be familiar with. He mentioned that he preferred to use another term. 
Survey question ten asked the students to rate the difficulty of the survey. The frequency of responses to the question regarding the level of difficulty of the survey are:

$\begin{array}{ccccc}\text { Very Difficult } & \text { Difficult } & \text { Average } & \text { Easy } & \text { Very Easy } \\ 0(0 \%) & 15(71.43 \%) & 5(28.81 \%) & 1(4.76 \%) & 0(0 \%)\end{array}$

At a rate of $71.43 \%$, most students responded that the survey was difficult. No students felt it was "Very Difficult" or "Very Easy". The one student who felt the survey was "Easy" answered 4 of the 9 correctly; $44.44 \%$.

\section{Design and Development Process}

During the design and development of the project, numerous types of data regarding the work flow and processes were collected and examined. For example, team collaboration data logs were kept that included primarily notes from the biweekly meetings and thoughts on the process as a whole kept by Ornelas. Ornelas and other team members noticed that there were certain patterns evident as we progressed through the design process as an interdisciplinary team. For instance, we had one occasion during which a discussion on images we wanted to include in a PowerPoint involved roughly ten minutes on what a water particle should look like. All project documents also were archived and available to the team, including all prototype versions, content outlines, original proposal, human subjects applications, draft instruments, etc.

More details on these design and development processes will be discussed in the findings section to follow.

The team started working on the content in March of 2012. The SMEs (engineering subject matter experts) provided the education students with four textbooks:

1. Geotechnical Engineering: Principles and Practices by D.P. Coduto, M.R. Yeng and W. Kitch.

2. Principles of Geotechnical Engineering by B. M. Das 
3. An Introduction to Geotechnical Engineering by R. D. Holtz, W. D. Kovacs and T. C. Sheahan

4. Soils and Foundations by C. Liu and J. B. Evett.

The instructional designers found the reading to be confusing. The content was relevant to the field of geotechnical engineering but deciphering what content to include in our learning module proved to be difficult. Sadauskas and Ornelas approached the engineers for help regarding this. An epiphany of sorts was reached by the engineers. They began to understand that the material needed to come more from them and the instructional designers' job was to develop the material in final form in a manner that minimized the amount of confusion. Struggling with the content was also helpful for the designers because that experience enabled them to relate to the struggling learner who is exposed to new material.

Houston took it upon herself to write up some material she wanted included in the Axis Translation PowerPoint. Ornelas and Sadauskas proceeded to develop the presentation. This was a more effective method for completing the task but there were still flaws. The material needed to be summarized because there was too much to include in a presentation, as when using a presentation tool such as PowerPoint as a lecture tool, it is important to be as concise as possible.

Once the presentation was completed Houston reviewed it and found that the message she wanted to deliver in the presentation was lost in translation when Ornelas and Sadauskas transferred it to the presentation. This was primarily because the material she wanted to include was summarized from her original notes. Yet another epiphany was reached when she realized she needed to provide the designers with material that was as close to what she wanted to say as possible and their job was to make sure that the content flowed well, made sense to the emerging learner, was free of errors and was presentable. 
We found that the SMEs need to be the ones who should generally begin the process of writing the material that needs to be included in the learning module. It is only natural that as the instructional designers work on the material that they will begin to pick up on the content, even content as complex as that described here, but it took this experience to make us all realize it. Ornelas and Sadauskas felt confident they could create the content but as it turned out, the content, at least initially, was difficult to understand. This was primarily because the background knowledge they came in with regarding geotechnical engineering was limited. Ornelas knew simple concepts like footing in building foundations, but when it came to the complexities of the soil-water content curve and stress states, he was at a loss.

One simple, yet relevant change was suggested by Ramirez, then an undergraduate student, once the slides were completed. Below is a slide from the original example:

\section{Stress State Variables}

We can combine these three stresses into two measurable "net" stress state variables, both of which tend to keep the grains together:

- The "net" total stress $\sigma \mathrm{u}_{\mathrm{a}}$

- The matric suction $\left(\mathrm{u}_{\mathrm{a}}-\mathrm{u}_{\mathrm{w}}\right)$

Figure $2 \mathrm{a}$

Figure 2a. Example of an original version of a basic content slide. 
He suggested that we make a change to a white background, as shown below.

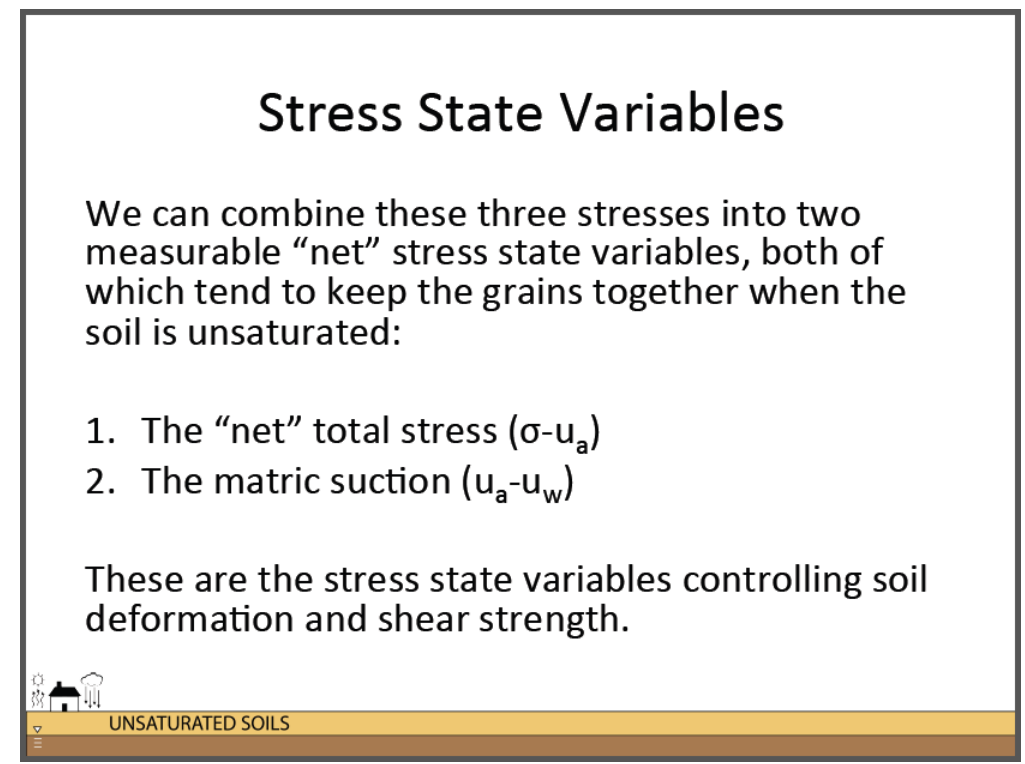

Figure 2b

Figure 2b. Redesign of the "look and feel" of a basic content slide.

This simple suggestion made an important difference, from a student's perspective, because, as he pointed out, if a student were to make copies of this 42 -slide presentation and the background were black, a good amount of ink would be required just to print it. The second example requires a lot less ink, even if the student chose to print it in black and white. Ornelas suggested we use the "Unsaturated Soils" header created by Sadauskus for each presentation, thus creating an "Unsaturated Soils" presentation template, Figure 2b. This was relevant because we felt that when a student saw this header they knew unsaturated soils was the topic being covered. We felt that consistency makes for a better learning module. Sadauskus offered an even better idea to place the header at the bottom of the slide, thus making it a footer. 


\section{Findings and Implications of Our Project Thus Far}

When professionals in one discipline take on a project there is a certain process they may anticipate using for development, that is, an idea of how they think things will work. However, interdisciplinary projects often require unexpected processes and may yield unexpected findings. This may be the case because the team runs into unexpected roadblocks. These processes and findings may be useful to many interdisciplinary research and development teams.

As an interdisciplinary team, we found many things that worked and some that did not. Our findings exemplify aspects of learning on such teams. The use of collaborative tools also yielded helpful techniques, as well as some frustrations. Such frustrations were caused by the glitches, either real or perceived, that we kept running into, which at times quelled some of the team members' enthusiasm about the tools. Work pacing and the requirements of collecting data on human subjects, our learners, were other areas on which the team experienced frustration, and subsequently, growth. Our comfort zone was also compromised, to a certain extent, but in that struggle we learned, and continue to learn, things we may not have, had we not taken on the challenge of this project.

\section{Learning From 0ther Professionals.}

The process of education professionals working with different types of engineers proved to be an enlightening experience for both sets of professionals. The education RAs developed a better understanding of the material. As they continued to develop the modules, some of the material became more familiar. They were able to work at a steadier pace as they continued to develop the presentation and lecture material. Ornelas felt like he understood approximately 30 to $40 \%$ of the material being created. For example, while reviewing results on an Excel spreadsheet on soil sample tests Ramirez was working on, the engineers were engaged in a 
discussion on figures that for the education professionals was somewhat foreign. Ornelas mentioned that although he understood the idea, finding the optimal soil type and characteristics, the specifics of the spreadsheet were difficult to understand.

Yet, there was now a level of comprehension that prior to working on this project would not have been present. The educators also began to pick up on basic concepts in geotechnical engineering, such as the three phases of soil, air and water and how they interact with each other and with pressure, for instance, atmospheric. There is also the effect of pore water pressure on soil properties and how pressure can affect soil when a structure is added to it.

This was also the case with the engineers. There were several occasions during which the education experts discussed concepts and tools they found useful, yet the engineers went through a learning curve in regards to these that the education people helped them overcome. One example was the use of Bloom's taxonomy (Bloom, Englehart, Furst, Hill, \& Krathwohl, 1956) as a basis for developing learning outcome statements (objectives). Another example is that one engineering team member found the use of Google Documents very helpful not only with this project, but with others as well. A third example involved a survey question created by Houston that was revised to be easier for students to answer by editing it into two clearer survey questions.

Members of the engineering team also expressed, on several occasions, learning new techniques in the design and development of material. One example involved the use of clear phrases and terminology for novices. Another was how to more clearly build instructions for students. These areas were to be particularly important in this project in that the learning materials are being developed to be flexibly incorporated by multiple faculty at multiple 
universities, who are likely to be teaching with different textbooks and using different instructional techniques.

\section{Collaborative Design Tools}

The Google Drive suite was one tool used by the team. It was effective for team collaboration on documents with instructional material and presentation-generating work using Google Presentations. However, the collaboration was also accompanied by some frustration, stemming primarily from the comment feature. For example, there were cases in which the engineering SMEs read through the first draft of the matric suction presentation and left some very insightful and productive comments, only to have these comments disappear in later versions. Formatting was another problematic issue; one team member would work on the presentation but somehow font types, sizes and alignments were unexpectedly changed.

Another frustration likely arose not necessarily from the tool itself, but due to the tool's seemingly slow response, more than likely due to limitations in Internet connections.

\section{Working Outside of Your Comfort Zone}

As content novices in the field of geotechnical engineering, overall, and unsaturated soil mechanics, more specifically, there was a learning curve that the Educational Technology and Design experts experienced, as mentioned before. The design experts were aware that there would be this learning curve, but the realization of how wide it would be came as a bit of surprise. It was this realization that made them re-evaluate their work processes. While working on the content for the learning modules, specifically the matric suction and Axis Translation material, the educational design experts struggled, primarily due to their concern that the material they were developing could contain errors. For instance, once the first draft of the matric suction PowerPoint was completed the Principal Investigator on the project found not 
only flaws in the material, but that the message she was trying to get across in the material was "lost". We found that having the SMEs readily available to review material as it was built was quite beneficial to the success of the project from the standpoint of both material accuracy as well as time on task.

\section{Working at a More Efficient Pace}

One issue that kept surfacing was the anxiety the team felt with regard to how much work was being accomplished. The instructional design process can be slow and we felt that it needed to progress at a more efficient rate. For instance, while working on the design of the presentation on matric suction the educational designers felt the process was proceeding rather slowly because of the tools used. Both of the education research assistants had Macbook Pro computers, but one was using PowerPoint for Macintosh while the other was using Keynote. It turned out that while the two collaborated on the presentation only one could edit the presentation. Both would have input on content and design of the presentation but it was painfully slow. You may wonder, "Why not use Google Presentations?", but as mentioned before, the use of it was less effective than hoped. We felt it would be better to develop the materials using the same development software, considering the aforementioned issues with Google Drive and the transfer of content from that tool to a Mac or PC. We decided it would be more efficient if one installed PowerPoint for Macintosh and they both worked on separate presentations, one on matric suction and the other on axis translation.

Another issue that arose was the team's editing process. Each time a member of the team would edit a presentation the format was thrown off. For instance, when a design expert gave one of the SME's an updated copy and the SME subsequently provided edits, often the formatting 
was changed. The team felt a consistent format would provide a better instructional tool, but if fonts and alignments were continually changed, that advantage would be lost.

One final point we would like to add would be the meeting process. As a team, we met every two weeks. For the spring semester of 2012 the team was able to physically meet. At first we felt we were progressing along, especially as we hammered out the survey, but once we started developing the learning material the pace seemed to slow significantly. Frustration with the slow process was prevalent among the team members. It turned out, as mentioned before, that the learning gap suffered by the designers was too wide to overcome by themselves. Once the engineers realized what was needed by the education team members, the pace improved significantly.

Another learning experience that proved to be somewhat frustrating in the early stages was the requirements of collecting human subject data, that is, the Internal Review Board (IRB) process. When dealing with human subjects an IRB application needs to be submitted to the review board for approval prior to the collection of any data, including the survey process. Each member of the group also had to complete the Collaborative IRB Training Initiative (CITI) Human Subjects Training Program. Although the CITI training gave us valuable information on the correct method for collected data on human subjects, team members agreed that this was a tedious, legal process. Savenye, Ornelas and Sadauskas had already completed the process from previous projects they had worked on, however Houston, Zapata and Garrett still had to complete it. This proved to be a source of frustration, one that the education professionals could sympathize with, having gone through that process already. Fortunately, the process did not delay project work, as we all completed the required CITI training while we were still developing some of the instruments. 


\section{The Flexibility of Content When the Learning and Instruction Settings Differ}

The team's job is to design a learning module that effectively covers the topic of unsaturated soil mechanics. The challenge, other than that of creating the learning materials, is to create a learning module that covers the material required, yet is not so rigid in content that an instructor in geotechnical engineering would have difficulty in incorporating the content into his or her course. This flexibility of use presents a challenge because, although the content in geotechnical engineering classes is relatively the same, the way, order and relevance of content used varies as much as the variation of the instructors teaching this course. There is also the additional task of creating content that is flexible enough to be incorporated in courses at multiple universities.

Having both the Tempe Cell and oedometer-type pressure plate laboratory material available to the instructor relates directly to the flexibility we feel is important while developing this learning module. Ramirez, for example, has been conducting tests on soil samples prevalent in the United States Southwest. This sample type, however, may not be as readily available when one is teaching in the Midwest, Northeast or the South. With that in mind we found it is important to offer the instructor the characteristics of the soil that would yield the desired results for this learning module; that is, the students being able to complete the test in a reasonable amount of time and under the matric suction range suitable for the devices available. This goes back to the discussion the engineering team had on Ramirez' results spreadsheet. Now that he has successfully conducted the tests we feel confident that we can recommend the type of soil characteristics that is best suited for our learning material.

Another consideration was that of when to place this material into an already existing curriculum. As we all know, instructors who have taught material for some time prefer to set up 
their own semester course outline. Introducing new material is often difficult given the limited amount of time available in a semester. If you couple that with the possible compromise of an instructor's comfort zone the task becomes even more problematic.

A third consideration was that of material delivery. Delivery, or teaching, styles can vary almost as much as do instructors. Keeping that in mind, we decided to offer some options to the instructors in the form of presentations, reading recommendations, and laboratory sessions with instructions. One laboratory module will also include an instructional video uploaded to YouTube that a student in the laboratory can even view on their smartphone. This video gives learners the opportunity to pause, rewind and fast forward to parts of the video they need more time to understand, missed or already know, respectively.

\section{Conclusion}

Ideas on paper do not always pan out in the field. The team chose a number of different collaboration tools, ones that did not work and others that did, but were a cause of frustration for some of the team members. As with any new content and technology, there was a learning curve that the team had to overcome. One was the use of Google Documents. This tool was effective, but the team seemed to drift away from it as the project progressed. This may have been because once the design team had some learning material to work with and their need to collaborate as often with the SMS's diminished, thus the tool became less necessary.

Google Presentations was another tool used by the team. This tool was less effective for the team than was Google Documents in that the team ran into issues of software clashes. In order to remedy this, the instructional designers decided to continue editing the material, mostly

looking at the design with some content taken into consideration. They continued the edits of the 
first two presentations on their own to avoid the problem of font changes and text alignment that we kept running into.

The team processes, too, over time have become streamlined, as the team members in education and engineering learned each other's limitations and came to rely on each other's professional strengths.

As the team moves into its final year of development and testing of the modules, additional baseline data are being collected and we continue to fine-tune the design. The materials, in prototype form, are being implemented at ASU and the partner universities. Learning data and attitudinal data, from both students and instructors will be used to improve the final form of the materials. The goal will be to enhance the usefulness of the materials for instructors at any university who wish to add to their students' knowledge of geotechnical engineering for unsaturated soils.

\section{Acknowledgments}

This project was funded by a grant from the NSF TUES program under Award \# 1044012 "Advancement of Unsaturated Soils Theory into the Undergraduate Civil Engineering Curriculum” - PI Houston, Sandra L., Savenye, Wilhelmina C., Zapata, Claudia E.

Any opinions, findings, and conclusions or recommendations expressed in this material are those of the authors and do not necessarily reflect the views of the National Science Foundation. 


\section{References}

Bloom, B. S., Englehart, M. D., Furst, E. J., Hill, W. H., \& Krathwohl, D. R. (1956). Taxonomy of educational objectives: the classification of educational goals: Handbook I: Cognitive Domain. New York, Longmans, Green.

Coduto, D. P., Yeng, M.R. , \& Kitch, W. A. (2010). Geotechnical Engineering: Principles and Practices, 2/e. Prentice Hall.

Das, B. M. (2009). Principles of Geotechnical Engineering. $7^{\text {th }}$ edition. CL-Engineering.

Dick, W., Carey, L., \& Carey, J. O. (2005). The Systematic Design of Instruction. $6^{\text {th }}$ edition. Boston, MA: Pearson.

Fredlund, D. G., Rahardjo, H., \& Fredlund, M. D. (2012). Unsaturated Soil Mechanics in Engineering Practice. John Wiley \& Sons.

Gagne, R. M., Wager, W. W., Golas, K. C. and Keller, J. M. (2005). Principles of Instructional Design. $5^{\text {th }}$ edition, Belmont, CA: Wadsworth/Thomson Learning.

Holtz, R. D., Kovacs, W. D., \& Sheahan, T.C. (2010). An Introduction to Geotechnical Engineering, 2nd Edition, Upper Saddle River, NJ: Pearson Prentice-Hall.

Liu, C. , \& Evett, J.B. (2007). Soils and Foundations. $7^{\text {th }}$ edition. Prentice Hall.

Merrill, M. D. (2007). First Principles of Instruction: A Synthesis. In R. A. Reiser, \& J. V. Dempsey (Eds.), Trends and issues in instructional design and technology, $2^{\text {nd }}$ edition, Upper Saddle River, NJ: Prentice Hall.

Padilla, M., Perera, Y. G., Houston, W., and Fredlund, D. (2006). Quantification of Air Diffusion through High Air Entry Disks, Proc. Of the $4^{\text {th }}$ International Conf. on Unsaturated Soils, Carefree, AZ, ASCE, pp 1852-1863.

Terzaghi, K. (1936). The shearing resistance of saturated soils, Proc. of the First International Conference on Soil Mechanics, Vol. 1, pg $54-56$.

Van Merrienboer, J. J. G, \& Kirschner, P. A. (2007). Ten Steps to Complex Learning. Mahwah, NJ: Lawrence Erlbaum.

Zapata, C.E. \& Houston, S.H. (2010). Implementation of Unsaturated Soil Mechanics Survey Results through The United States Universities Council on Geotechnical Education and Research (USUCGER) Web-List. Unpublished report. Arizona State University. 